\title{
Servant Leadership and Follower Job Performance: The Mediating Effect of Public Service Motivation
}

Gary Schwarz, SOAS University of London

Alexander Newman, Deakin University, Australia

Brian Cooper, Monash University, Australia

Nathan Eva, Monash University, Australia

\begin{abstract}
:
This article advances our understanding of the effects of servant leadership, an employee- and community-focused leadership style, on followers' public service motivation (PSM) and job performance. Based on social learning theory, we argue that by emphasizing to their followers the importance of serving others both inside and outside the organization and by acting as role models by serving others themselves, servant leaders enhance job performance by engendering higher PSM in their followers. A multi-level analysis of three waves of multisource data from a Chinese government agency reveals that PSM mediates the influence that servant leadership has on followers' job performance. The results are consistent with the theoretical predications that the altruistic behaviour displayed by servant leaders elicits higher levels of the altruistic behaviours that characterize PSM, which in turn increases job performance. Hence, this study contributes to our overall understanding of how leadership drives performance in the public sector.
\end{abstract}

Acknowledgements: 
This is the accepted version of an article accepted for publication in Public Administration Vol. 94 No. 4, 1025-1041. For

the full citation information and a link to the final Wiley published article please see: http://dx.doi.org/ 10.1111/padm.12266

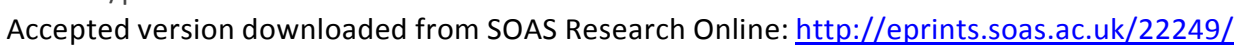

We would like to thank Tom Christensen and Lisheng Dong for their feedback on an earlier draft of this article and Jian Feng for help with the data collection.

\section{INTRODUCTION}

Faced with a turbulent and uncertain operating environment (Boin and 't Hart 2003), the pressure 'to do more with less' has left many public service organizations with the task of redefining their traditional roles and responsibilities (Vermeeren et al. 2014). This requirement has led them to examine effective methods of increasing performance (Fernandez and Moldogaziev 2011). Public service motivation (PSM), defined as 'an individual's predisposition to respond to motives grounded primarily or uniquely in public institutions and organizations' (Perry and Wise 1990, p. 368), has generally been found to increase job performance amongst employees (Bright 2007; Vandenabeele 2009; Bellé 2013). With this finding in mind, the impact that leaders have on raising PSM to drive performance has received increasing attention in the literature (Wright et al. 2012).

Leadership has been broadly defined as 'an influence relationship among leaders and followers who intend real changes that reflect their mutual purposes' (Rost 1993, p. 124). Over the last two decades, researchers have begun to examine the specific leadership behaviours exhibited by supervisors and how they influence employee attitudes and behaviours (Van Wart 2013). In line with this behavioural approach to leadership research, the present study examines the role of servant leadership in enhancing the job performance of followers through fostering higher levels of PSM in the Chinese public sector. This style of leadership, in which leaders strive selflessly to assist others before themselves and encourage their followers to do the same (Greenleaf 1977), has been the focus of recent research in the Chinese public sector (Han et al. 2010; Miao et al. 2014). In his essay The Institution as Servant Greenleaf (1972, p. 5) states that 'individuals who want to serve must, on their own, 
This is the accepted version of an article accepted for publication in Public Administration Vol. 94 No. 4, 1025-1041. For

the full citation information and a link to the final Wiley published article please see: http://dx.doi.org/ 10.1111/padm.12266

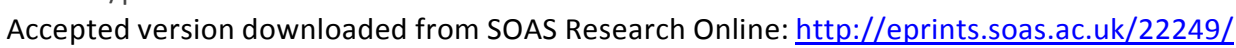

become institution builders where they are.' Following Greenleaf, we argue that servant leaders are institutional entrepreneurs (DiMaggio 1988), i.e., change agents who take a leadership role in making issues that they value legitimate, and who are also actively involved in the implementation of change (Battilana et al. 2009). Mahatma Gandhi, Mother Teresa and Nelson Mandela are prominent examples of servant leaders.

Instead of serving their superiors, which has been the traditional practice in the Chinese public sector (Dong et al. 2010), servant leaders emphasize the benefits of their followers and the community at large (Sendjaya et al. 2008). Although a growing body of research suggests that servant leadership may have positive effects on employee work outcomes such as job performance (Liden et al. 2008), prior research has not examined the mechanisms that link servant leadership to job performance in the public sector. Moreover, previous studies have not analysed whether servant leadership can be utilized to elicit higher levels of PSM amongst public sector employees. Servant leaders who set aside their selfinterest are particularly important for the Chinese government, given that rampant corruption has led to the arrest of several high-profile civil servants and the incarceration of thousands of other employees who have damaged the legitimacy of one-party rule (Dong et al. 2010).

Utilizing three waves of multi-source and multi-level data from a Chinese government agency, our study investigates whether followers' PSM acts as a mechanism that links servant leadership to the job performance of followers (see figure 1). Drawing on social learning theory (Bandura 1977), which stresses the importance of role modelling by the leader as a central process through which social influence occurs in the workplace, we propose that servant leadership will lead followers to exhibit higher levels of PSM. We argue that this behaviour in turn will lead followers to focus on serving the needs of those both inside and outside the organization and exhibit higher levels of job performance accordingly. 
This is the accepted version of an article accepted for publication in Public Administration Vol. 94 No. 4, 1025-1041. For the full citation information and a link to the final Wiley published article please see: http://dx.doi.org/ 10.1111/padm.12266

Accepted version downloaded from SOAS Research Online: http://eprints.soas.ac.uk/22249/

In the following sections, we first review the literature on servant leadership and PSM in light of the current Chinese institutional environment before developing the hypotheses accordingly. We then discuss how the data were collected and analysed, in addition to the results of the study. Finally, we discuss the theoretical and practical implications of the study before concluding with potential avenues for future research.

\section{SERVANT LEADERSHIP}

Servant leadership is defined as a holistic and altruistic approach to leadership that is characterized by the leader's central focus on the aspirations and needs of his or her followers (Van Dierendonck 2011). Within the organization, managers display servant leadership behaviours by committing to the personal and professional growth of employees above the financial gains of the organization (Graham 1991). For example, a servant leader will listen to and understand the aspirations of his or her followers and will mentor followers to achieve these goals. Although other leadership styles that focus on followers have started to emerge, servant leadership remains unique, given that helping the followers reach their full potential and serving the needs of wider stakeholder groups are at its core (Sendjaya et al. 2008). Followers in turn view the servant leader as a role model and mirror his or her behaviours, thus becoming servant leaders themselves (Greenleaf 1977). Servant leadership behaviours have been shown across multiple studies and countries to be a predictor of positive employee and organizational outcomes across cultures and contexts (Han et al. 2010; Liden et al. 2015). Specifically, past research has demonstrated that servant leaders are effective in highly bureaucratic organizations, given that they seek to empower and mentor employees regardless of the levels of organizational centralization and formalization (Eva et al. 2013). In explaining the effects of servant leadership on follower outcomes, prior research has typically drawn on social learning theory (Hunter et al. 2013; Liden et al. 2014). 
This is the accepted version of an article accepted for publication in Public Administration Vol. 94 No. 4, 1025-1041. For the full citation information and a link to the final Wiley published article please see: http://dx.doi.org/ 10.1111/padm.12266

Accepted version downloaded from SOAS Research Online: http://eprints.soas.ac.uk/22249/

Social learning theory proposes that individuals learn from observing and emulating the attitudes, values and behaviour of important role models in their environment such as their leader (Bandura 1977). In the workplace, leaders are an important source of role modelling due to their status and power over followers, especially when they are perceived as a credible role model (Hunter et al. 2013). Through communicating to subordinates what types of behaviour are expected and aligning rewards to incentivize such behaviour, leaders significantly influence their followers' attitudes and behaviours. Compared to other forms of leadership, servant leaders are more likely to be viewed as credible role models, given that followers believe they act altruistically and are motivated to serve others without expecting anything in return (Sendjaya et al. 2008). Indeed, in line with social learning theory, the follower emulation of leader behaviour has been highlighted as a key dimension of servant leadership in previous work (Graham 1991).

\section{Servant leadership in the Chinese public sector}

Since the beginning of China's reform and opening up policy in 1978, structural changes have led to continuous pendulum swings between concentrating powers in Beijing and granting local autonomy (Xue and Liou 2012). In 1988, the Ministry of Personnel was created, and in 1993 the Provisional Regulations on State Civil Servants established a new civil service system that amended the selection, evaluation, training, promotion, and compensation of civil servants (Burns 2007). In 2006, a new Civil Service Law took effect that had two main objectives: to strengthen the Chinese Communist Party (CCP)'s control over the bureaucracy by avoiding a Western-style politics-administration dichotomy and to establish a meritocratic personnel system designed to increase efficiency and effectiveness (Wang 2012; Ma 2015). 
This is the accepted version of an article accepted for publication in Public Administration Vol. 94 No. 4, 1025-1041. For the full citation information and a link to the final Wiley published article please see: http://dx.doi.org/ 10.1111/padm.12266

Accepted version downloaded from SOAS Research Online: http://eprints.soas.ac.uk/22249/

In this rapidly changing environment, Chinese public sector employees are constantly asked to perform new tasks, adhere to new evaluation systems and address increasingly demanding citizens. This volatile and uncertain institutional arrangement may demoralize and discourage Chinese civil servants, who have limited recourse to supervisors who nurture their talents, provide support, consideration, and encouragement and help them face such mounting challenges. Dong et al. (2010, p. 101) described the traditional supervisor orientation in the Chinese public sector as follows: 'Public servants only serve their bosses. They fix their eyes upward, turn a blind eye downward, and try desperately to weigh the boss's intention because the only thing that matters is their promotion.' Servant leaders fundamentally change this orientation. Their focus on the needs of employees represents a divergent change in a field that has traditionally been characterized by hierarchical order and top-down decision-making (Xue and Liou 2012, Li 2015). Hence, servant leaders who modify the 'rules of the game' and reverse this logic may be considered institutional entrepreneurs (DiMaggio 1988) who initiate and actively participate in activities that alter the predominant organizational practices (Battilana et al. 2009).

Ehrhart (2004) describes servant leadership as having seven dimensions, which have been empirically validated across different organizational and cultural contexts (Hunter et al. 2013). Recent research suggests that these servant leadership dimensions are increasingly being practiced in the Chinese public sector (Han et al. 2010). Miao et al. (2014) found that supervisors in Chinese public organizations focus on the needs of followers above and beyond their organization's interests, which provides support for the putting subordinates first dimension. The Civil Service Law states that 'all civil servants should be trained on the job for updated knowledge and skill improvement' (Zhang and Zhou 2010, p. 156), which is compatible with the dimensions of helping subordinates grow and succeed and having conceptual skills. Chapter five of the Civil Service Law has added integrity to the 
This is the accepted version of an article accepted for publication in Public Administration Vol. 94 No. 4, 1025-1041. For

the full citation information and a link to the final Wiley published article please see: http://dx.doi.org/ 10.1111/padm.12266

Accepted version downloaded from SOAS Research Online: http://eprints.soas.ac.uk/22249/

performance evaluation process in Chinese public sector organizations (Liu and Dong 2012).

Behaving ethically is especially needed in light of the rampant corruption that plagues the

Chinese government and has caused a legitimacy crisis for the CCP (Dong et al. 2010). The

Civil Service Law stipulates that training courses for civil servants should increase employees' ability to resist corruptive tendencies (Zhang and Zhou 2010). Creating value for those outside the organization, is important for the Chinese government given that it aims at increasing citizen satisfaction with the delivered public services (Dong et al. 2010) and promoting a 'harmonious society', a socially balanced, ideal state advocated by then Chinese President Hu Jintao in which conflict among all stakeholders is minimized (Holzer and Zhang 2009). Forming relationships with subordinates based on open communication is practiced equally in a relational culture such as China (Liu and Dong 2012). Finally, Huang et al. (2010) demonstrated that participative leadership behaviour that empowers subordinates elicited higher organizational commitment among subordinates in Chinese state-owned enterprises.

\section{Public service motivation in China}

Recently, several studies have analysed PSM in China (e.g., Kim et al. 2013, Ko and Han 2013; Liu et al. 2015). Liu et al. (2008) found evidence for the existence of three of Perry's (1996) PSM dimensions (attraction to public policy making, commitment to the public interest, and self-sacrifice) amongst Chinese civil servants. Liu and Perry (2016) demonstrated that PSM was positively associated with job satisfaction, community citizenship behaviour, and the organizational identification of Chinese public servants. Likewise, Liu et al. (2015) showed that public employees in China were more satisfied with their jobs when PSM was high.

Researchers argue that, for the Chinese, the motivation to work for the government is deeply rooted in Confucianism (Han et al. 2010). Drawing on Confucianism, the word 
This is the accepted version of an article accepted for publication in Public Administration Vol. 94 No. 4, 1025-1041. For

the full citation information and a link to the final Wiley published article please see: http://dx.doi.org/ 10.1111/padm.12266

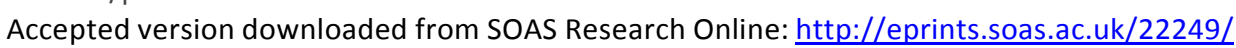

'public' has four distinct connotations: unselfishness and impartiality (making decisions that are good for the whole, rather than the individual), fairness, a community of people sharing interests, and a government position (Ko and Han 2013). Public service positions in China are frequently considered more prestigious than private sector jobs because in Confucian tradition being appointed to a civil service role bestows great honour onto oneself and one's family (Ko and Han 2013). Hence, the attractiveness to work in the public sector is very strong in China (Wang 2012). In 2015, for example, 1.39 million applicants competed for 27,817 entry-level positions in the annual nation-wide civil service examinations (Liu 2015). On the basis of this cultural and historical background, China offers a unique perspective in understanding the antecedents and outcomes of PSM.

\section{Servant leadership and public service motivation}

Although a growing amount of research has examined the linkages between PSM and employee work outcomes that are of benefit to organizations, such as job performance, organizational commitment and job satisfaction (Bellé 2013; Vandenabelee et al. 2014), the antecedents of PSM have received less attention (Bozeman and Su 2015). One factor that has been demonstrated to be crucial to the development of PSM amongst public servants is an employee's interaction and relationship with his or her leader (Wright et al. 2012; Chen et al. 2014; Vandenabelee et al. 2014). Although prior research has focused on the relationship between transformational leadership practices and PSM (Kroll and Vogel 2014; Wright et al. 2012), the link between servant leadership and PSM has not been examined to date.

There are several differences between servant leadership and the transformational leadership approach that has been the subject of many studies in the public sector (e.g., Wright et al. 2012, Van Wart 2013; Kroll and Vogel 2014). Originally conceptualized by Burns' (1978) in a study on political leaders, transformational leadership emphasizes the 
This is the accepted version of an article accepted for publication in Public Administration Vol. 94 No. 4, 1025-1041. For

the full citation information and a link to the final Wiley published article please see: http://dx.doi.org/ 10.1111/padm.12266

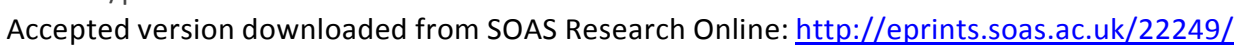

importance of articulating a compelling vision (Bass 1985) and focuses on employees mainly to the extent it is beneficial to turn this vision into reality. Given that its dominant allegiance is to the organization (Van Dierendonck 2011), it views employees primarily as a means to an end (Ehrhart 2004). Compared to transformational leaders, servant leaders focus on humility, authenticity, and interpersonal acceptance (Van Dierendonck 2011) and view employees as an end in themselves, focusing on their personal and professional development and helping them reach their potential. Servant leaders trust that followers will do what is necessary for the organization (Stone et al. 2004).

Servant leaders also place a greater emphasis on morality and ethics than transformational leaders do (Graham 1991). Due to their ethical focus, the servant leader takes into account the wide range of stakeholders affected by his or her decisions (Liden et al. 2008), a behaviour that is not an explicit component of transformational leadership. As stakeholders play an important role in the public sector (Bryson 2004), servant leadership seems particularly appropriate for public organizations.

What the servant leadership model offers is a similarly altruistic calling that characterizes PSM and a desire to foster altruistic behaviours in employees (Graham 1991; Stone et al. 2004). Altruism is the cornerstone of numerous PSM definitions, which state that the concept of PSM is deeply rooted in one's desire to serve others (Perry et al. 2010). Stazyk and Davis (2015) find that PSM is positively correlated with ethical obligations rooted in integrity and virtue. Similarly, servant leaders are characterized by their ethical and selfsacrificing behaviours, compassion for others, and altruistic nature (Sendjaya et al. 2008). Drawing on previous work that has utilized social learning theory (Bandura 1977) to highlight how servant leaders induce their followers to become servants themselves (Hunter et al. 2013; Liden et al. 2014), we propose that due to the altruistic nature of servant behaviour, servant leaders will induce followers to exhibit higher levels of PSM. 
This is the accepted version of an article accepted for publication in Public Administration Vol. 94 No. 4, 1025-1041. For the full citation information and a link to the final Wiley published article please see: http://dx.doi.org/ 10.1111/padm.12266

Accepted version downloaded from SOAS Research Online: http://eprints.soas.ac.uk/22249/

Social learning theory posits that individuals learn vicariously, i.e., by watching others. Through the observation of positive behaviours by a credible role model, followers learn that these are required behaviours within their social context and will seek to emulate them (Bandura 1977). They will seek to model the behaviours of their leader's due to either the leader' position or because they see the leader as a mentor worth imitating (Graham 1991). In particular, followers will seek to model the leader's behaviours when they believe the leader possesses positive and attractive characteristics, which has been shown to be the case with servant leadership (Liden et al. 2014). Previous research showed that followers who witness their leader displaying service to the community and the promotion and empowerment of employees, are, in turn, motivated to model these behaviours through helping colleagues and the community (Hunter et al. 2013). Liden et al. (2014) argued that followers learn to serve others through a 'trickle down' effect, where the leader demonstrates the desired behaviours and motivates employees to emulate such behaviours.

Although research has not yet examined the influence of servant leadership on PSM at the individual level, empirical research at the group level suggests that servant leadership may influence employee work outcomes through the development of a 'service climate' (Hunter et al. 2013) or 'serving culture' (Liden et al. 2014) within organizations. For example, Hunter et al. (2013) find that servant leadership positively influences the service climate within an organization by fostering a culture that emphasizes the importance of taking an interest in the growth and development of others. Similarly, Liden et al. (2014) establish that servant leadership promotes a serving culture amongst members of an organization. In addition, other researchers have argued that servant leaders increase their followers' motivation to serve the public. For example, in his original work on servant leadership, Greenleaf (1977) notes that the best test of a servant leader is whether his or her followers are more likely to turn into servants themselves. Similarly, Liden et al. (2008) 
This is the accepted version of an article accepted for publication in Public Administration Vol. 94 No. 4, 1025-1041. For

the full citation information and a link to the final Wiley published article please see: http://dx.doi.org/ 10.1111/padm.12266

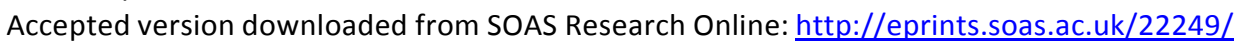

argue that servant leaders prepare the organization and its members to make contributions to society. As PSM is characterised by the motivation to serve the public (Perry and Hondeghem 2008), a servant leader should have a positive effect on followers' PSM. This leads us to the following hypothesis:

Hypothesis 1: Servant leadership will be positively related to follower PSM.

\section{Servant leadership, public service motivation, and job performance}

In addition to influencing PSM through social learning processes (Bandura 1977), we also expect servant leadership to influence the job performance of followers through the mediating mechanism of PSM. This expectation is consistent with social learning theory (Bandura 1977) in that it suggests that servant leaders act as role models to followers who emulate their attitudes regarding the importance of serving clients and other organizational stakeholders (Hunter et al. 2013). This behaviour in turn should result in higher levels of PSM amongst followers, lead them to exert extra effort to assist their clients and other employees in the organization and manifest itself in higher levels of followers' job performance. Although prior empirical work has not examined the mediating effects of PSM on the relationship between servant leadership and job performance, there is growing evidence that links PSM to job performance in the public sector (Perry and Wise 1990; Bellé 2013;).

In Perry and Wise's (1990, p. 37) seminal work, the second proposition is that 'in public sector organizations, PSM is positively related to individual performance'. In public sector roles, people with high levels of PSM are able to live out their altruistic values, creating an intrinsic motivation to perform at a higher level (Wright and Grant 2010). In the 25 years since Perry and Wise's proposition was formed, a number of studies have empirically explored this relationship. Apart from Caillier (2010), they demonstrate a positive 
This is the accepted version of an article accepted for publication in Public Administration Vol. 94 No. 4, 1025-1041. For the full citation information and a link to the final Wiley published article please see: http://dx.doi.org/ 10.1111/padm.12266

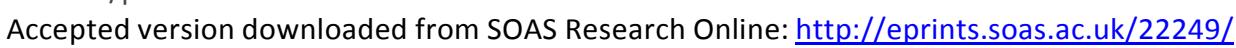

relationship between PSM and performance across multiple cultures and organizations (e.g., Bright 2007; Leisink and Steijn 2009; Vandenabeele 2009; Bellé 2013).

One of the major criticisms of previous PSM job performance studies is that instead of supervisor-rated mechanisms, self-reported mechanisms of performance are utilized (e.g., Bright 2007; Leisink and Steijn 2009; Vandenabeele 2009). In a review of the PSM literature, Perry et al. (2010) argue that this reliance on self-reports is a fundamental issue in the public service literature that needs to be addressed. Studies such as Bellé's (2013) experimental design have started to combat this methodological shortcoming and display strong associations between PSM and job performance. This study further addresses this gap by utilizing supervisor-rated performance data.

In addition to the strong links between PSM and performance, servant leadership has been found to increase follower perceptions of their job performance (self-rated) by enhancing their customer orientation (Jaramillo et al. 2009). However, this research remains in its infancy, with servant leadership researchers focusing primarily on performance at the group level such as team performance (Liden et al. 2014). Furthermore, there remains a lack of understanding of the underlying social learning mechanisms that link servant leadership to performance outcomes (Van Dierendonck 2011). Considering that servant leadership behaviours should have a positive influence on PSM, we argue that PSM will have positive mediating effects on the relationship between servant leadership and the job performance of public sector employees. This argument leads us to the following hypothesis:

Hypothesis 2: PSM will mediate the relationship between servant leadership and follower job performance.

\section{METHODS}

\section{Sample and data collection}


This is the accepted version of an article accepted for publication in Public Administration Vol. 94 No. 4, 1025-1041. For the full citation information and a link to the final Wiley published article please see: http://dx.doi.org/ 10.1111/padm.12266

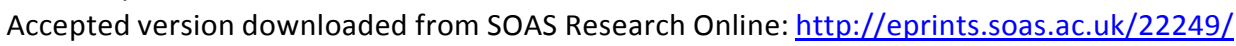

We collected survey data from a Chinese prefecture-level government agency in Zhejiang Province from two sources (supervisors and their immediate subordinates) across three different time periods in May and June 2014 to minimize common method bias (Podsakoff et al. 2012). The agency assures that private firms adhere to legally mandated quality and safety standards, for example, for special equipment. It inspects their operations, issues certifications, provides training sessions, and releases statistics to the public. The respondents came from all parts of the organizations. Prior to their distribution, the questionnaires were translated into Chinese from English by bilingual members of the research team using the back-translation procedure (Brislin 1993). Participants received a cover letter, paper-based questionnaire and return envelope at work. Each questionnaire was coded with an identification number to allow the researchers to match employee responses with those of their supervisor. To ensure confidentiality, participants were asked to seal the completed questionnaire in the envelope. At time 1, data on the control variables and servant leadership were collected. Two weeks later, at time 2, data on PSM were collected. At time 3, a further two weeks later, questionnaires were distributed to the immediate supervisors at work. The supervisors were required to rate the job performance of their subordinates.

A total of 249 matched subordinate/supervisor responses were received from 31 teams, representing an overall response rate of 83 per cent. The teams had an average size of eight members. The mean age of the subordinates was 33.07 years $(\mathrm{SD}=7.18)$, which is one year less than the average age of civil servants in Zhejiang province (Miao et al. 2014). 68 per cent were male and they had worked under their present supervisor on average for slightly less than four years $(\mathrm{M}=3.93, \mathrm{SD}=2.96)$. The mean organizational tenure was 6.90 years $(\mathrm{SD}=5.86)$

\section{Measures}


This is the accepted version of an article accepted for publication in Public Administration Vol. 94 No. 4, 1025-1041. For

the full citation information and a link to the final Wiley published article please see: http://dx.doi.org/ 10.1111/padm.12266

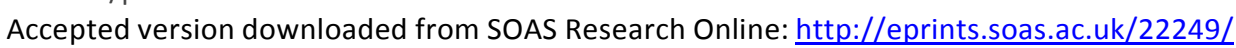

The study variables were measured using multi-item scales validated in earlier studies (see the appendix for a comprehensive list). They were all measured using 5-point Likert scales where $1=$ strongly disagree and $5=$ strongly agree.

Servant leadership. Servant leadership was measured using Ehrhart's (2004) 14-item scale. This measure has been widely tested and validated in prior studies (Hunter et al. 2013), including recent work on Chinese public servants (Miao et al. 2014). The Cronbach's alpha for this scale was .91 .

PSM. We measured PSM using the 5-item Merit Systems Protection Board scale used in previous work (Wright et al. 2012). The Cronbach's alpha for this scale was .84.

Job performance. Job performance was measured using the 3-item scale of Heilman et al. (1992). The Cronbach's alpha for this scale was .73.

Control variables. We included organizational tenure, length of time working under the present supervisor (both measured in years), and gender (coded $1=$ male, $0=$ female) as controls in line with previous research (Miao et al. 2014). Age was not included as a control variable, given that it was very highly correlated with organizational tenure $(r=.80)$.

\section{Method of analysis}

The current analysis follows recommendations by Liden et al. (2008) to examine servant leadership at the team level. This approach has regularly been applied in the recent servant leadership literature (e.g., Hunter et al. 2013; Miao et al. 2014). The rationale is that follower attitudes (PSM) and behaviours (performance) are influenced not only by the own relationship with the leader but also by the degree to which a follower believes their leader displays servant leadership behaviours consistently to other team members. If, on the contrary, a leader selectively displays servant behaviours across members, followers may feel concerned that the leader will not provide them with the benefits of servant leadership in the future. These fears of 'anticipatory injustice' (Shapiro and Kirkman 2001) may have as much 
This is the accepted version of an article accepted for publication in Public Administration Vol. 94 No. 4, 1025-1041. For the full citation information and a link to the final Wiley published article please see: http://dx.doi.org/ 10.1111/padm.12266

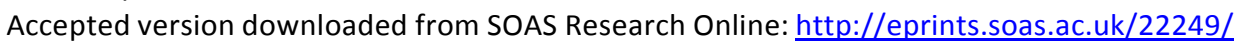

of an impact on current follower behaviours as actual unjust treatment. Consequently, our study aggregates servant leadership to the team level to capture the shared perceptions amongst team members of the supportive and altruistic nature of the leader to serve their followers and community.

To test our hypotheses, we conducted multi-level modelling with random intercepts. To facilitate the interpretation of the effect size, all of the variables were z-standardized prior to analysis. In effect, standardization is a form of grand mean centring that is commonly performed on predictors in multi-level analyses. Given that the number of level-2 units (teams) was relatively small, restricted maximum likelihood (REML) estimation was used (Tabachnick and Fidell 2013). The results of the evaluation of the regression assumptions of normality, linearity, the absence of multi-collinearity, and homoscedasticity were satisfactory.

\section{RESULTS}

\section{Confirmatory factor analyses}

All scale items, with their means, standard deviations, and standardized factor loadings, can be found in the appendix. The standardized factor loadings on each of the factors were excellent, averaging .71 for PSM, .65 for servant leadership, and .69 for job performance. We conducted a confirmatory factor analysis using LISREL 8.80 to establish the discriminant validity of the study measures. Table 1 shows that using robust maximum likelihood estimation, the hypothesized three-factor model (i.e., with items loading onto the corresponding factors of servant leadership, PSM and job performance) yielded a good fit to the data, Satorra-Bentler scaled $x^{2}(d f=206, N=249)=482$; $\mathrm{RMSEA}=.07$, TLI $=.96, \mathrm{CFI}$ $=.97$. Table 1 shows that the alternative two-factor and one-factor models had a poorer fit, 
This is the accepted version of an article accepted for publication in Public Administration Vol. 94 No. 4, 1025-1041. For the full citation information and a link to the final Wiley published article please see: http://dx.doi.org/ 10.1111/padm.12266

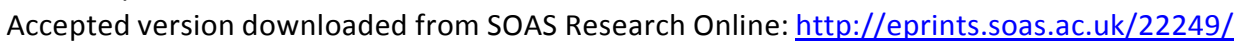

providing evidence of discriminant validity. Taken together, these results provide evidence of the construct validity of the measures used in this study.

[Insert table 1 here]

\section{Aggregation tests}

Following Ehrhart (2004), we conceptualized servant leadership as a team-level variable. The mean rwg (calculated using a uniform null distribution) was .96, indicating a high level of within-group agreement. The inter-rater reliability values of ICC(1) and ICC(2) were .14 and .56 , respectively. The ICC(2) estimate (which measures the reliability of the group means) was considered sufficient given the relatively small team sizes observed in the study. Taken together, these results provide support for the aggregation of servant leadership scores to the team level.

\section{Multi-level modelling}

Table 2 presents the means, standard deviations, and correlations of the study variables. The correlations for servant leadership, PSM, and job performance were all in the expected direction.

[Insert table 2 here]

Table 3 presents the results from the multi-level regression analyses that tested the hypothesized relationships. Of all of the control variables, only gender was related to PSM, suggesting that males had higher levels of PSM than females. None of the control variables were related to job performance. Hypothesis 1 predicted that servant leadership will be positively related to follower PSM. As indicated in table 3 (model 1), with controls included, 
This is the accepted version of an article accepted for publication in Public Administration Vol. 94 No. 4, 1025-1041. For the full citation information and a link to the final Wiley published article please see: http://dx.doi.org/ 10.1111/padm.12266

Accepted version downloaded from SOAS Research Online: http://eprints.soas.ac.uk/22249/

there was a positive cross-level relationship between servant leadership and $\operatorname{PSM}(\beta=.39, \mathrm{p}$ $<.01)$. Hence, hypothesis 1 is supported.

[Insert table 3 here]

Hypothesis 2 predicted that PSM will mediate the relationship between servant leadership and follower job performance. As noted above, servant leadership and PSM were positively related $(\beta=.39, \mathrm{p}<.01)$, as was PSM and job performance $(\beta=.14, \mathrm{p}<.05)$.

To test the hypothesized indirect (mediated) effect, we used a Monte Carlo simulation with the recommended 20,000 replications (Preacher and Selig 2012). A Monte Carlo simulation is a flexible method for constructing the confidence intervals for indirect effects, given that it can be used where non-parametric bootstrapping is not feasible, such as with multi-level or nested data. In contrast to resampling or bootstrap methods, a Monte Carlo simulation involves directly generating sample statistics from their joint parametric distribution. The Monte Carlo technique has been found to perform favourably with bootstrapping, and it rarely leads to divergent inferences of mediation (Preacher and Selig 2012). The estimated indirect effect of servant leadership on job performance through PSM was .05 $(95 \% \mathrm{CI}=.01$ to .11). Given that zero is not contained in the $95 \%$ confidence interval for the indirect effect, hypothesis 2 is supported. Finally, as indicated in table 3 (model 2), the direct effect of servant leadership on job performance was not statistically significant $(\beta=.01, p>.05)$, suggesting an inference of full mediation via PSM. The mediation model is presented in figure 1 .

[Insert figure 1 here]

\section{DISCUSSION}


This is the accepted version of an article accepted for publication in Public Administration Vol. 94 No. 4, 1025-1041. For

the full citation information and a link to the final Wiley published article please see: http://dx.doi.org/ 10.1111/padm.12266

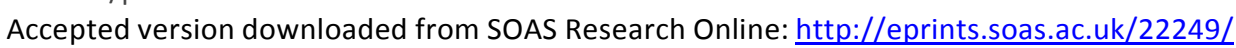

In line with social learning theory (Bandura 1977), our study establishes that servant leadership influences the job performance of Chinese public sector employees by enhancing their PSM. Instead of pleasing their superiors, which has been the traditional practice in the Chinese civil service, servant leaders focus on the wellbeing of their followers and the community at large. Thus, they are institutional entrepreneurs, i.e., endogenous sources of divergent change who advance the interests that they value highly but that are suppressed by existing logics (DiMaggio 1988). By doing so, servant leaders successfully address the paradox of embedded agency (Holm 1995), given that they enact change in the very institutions that condition their thinking and in which they are embedded (Greenleaf 1972). Thus, they demonstrate their reflective capacity as they detach themselves from the dominant superior-focused institutional arrangement and envision a follower- and community-focused alternative (Battilana et al. 2009).

The servant leaders' social position is an important enabling condition for institutional entrepreneurship (Battilana et al. 2009). Their position as supervisors in the organizational hierarchy provides them with resources that can be leveraged to further their interest and to mitigate the risks of deviating from taken-for-granted norms (Battilana et al. 2009). Their status as honest and trustworthy leaders due to their highly ethical conduct turns them into an important source of role modelling (Bandura 1977). Consequently, servant leaders are able to mobilize 'subsidiary actors' (DiMaggio 1988) who would like to become servant leaders themselves and are able to induce higher levels of PSM, thus increasing their job performance.

March and Olsen (1996) describe what they term the 'logic of appropriateness.' In their view, actors follow internalized rules of what is socially prescribed as natural, normal, and right regardless of a calculation of consequences. Thus, a particular leadership style may merely be adopted because it leads to reputation effects in the view of important actors in the 
This is the accepted version of an article accepted for publication in Public Administration Vol. 94 No. 4, 1025-1041. For

the full citation information and a link to the final Wiley published article please see: http://dx.doi.org/ 10.1111/padm.12266

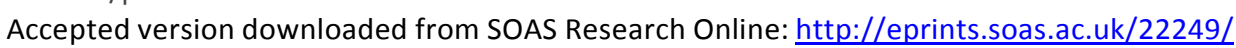

institutional environment and not because of its expected efficiency. Servant leadership may be implemented to gain legitimacy, for example, because then Chinese President Hu Jintao urged Chinese public sector employees to build a service-oriented government in which officials work selflessly for the benefit of the people and wider society (Holzer and Zhang 2009; Miao et al. 2014). Our findings demonstrate that simply because a public organization introduces a leadership style to accommodate new environmental expectations, it does not follow that the novel practice is inadequate in terms of performance (Entwistle 2011).

Although prior research has examined the effects of transformational leadership as an antecedent of PSM (Kroll and Vogel 2014; Wright et al. 2012), this study is the first to draw on social learning theory to examine how servant leadership drives PSM as followers emulate the attitudes of their leader (Bandura 1977). Servant leadership is distinct from transformational leadership as an antecedent due to the servant leader's altruistic motivations and self-sacrificing behaviours (Sendjaya et al. 2008). Therefore, we argue that our findings demonstrate that the leader can have a positive impact on PSM among Chinese civil servants, without running the risk of employee cynicism that may arise if employees feel that their desire to serve others is being exploited by the leader for the organization's gain, given that the servant leader shares values that are congruent with his or her followers and looks to nurture these values within them on a daily basis (Sendjaya et al. 2008).

The present study also makes a particular contribution by highlighting the role played by PSM in linking servant leadership to followers' job performance. Although prior research has investigated how servant leadership influences the work attitudes of interest to public sector organizations (Miao et al. 2014), our study is the first to examine the underlying social learning processes that link servant leadership to job performance in line with social learning theory (Bandura 1977). In terms of the servant leadership performance relationship on a broader scale, this study offers a unique perspective that focuses on individual job 
This is the accepted version of an article accepted for publication in Public Administration Vol. 94 No. 4, 1025-1041. For

the full citation information and a link to the final Wiley published article please see: http://dx.doi.org/ 10.1111/padm.12266

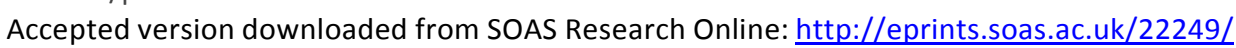

performance as opposed to group performance (Liden et al. 2014) and analyses this relationship in the Chinese public sector. Furthermore, this study extends previous PSM/job performance research by measuring the dependent variable of job performance by using supervisor ratings instead of by self-report. By utilizing a non-self-report measure of performance, we address one of the significant issues identified by Perry et al. (2010) in PSM/performance research

Our results have important practical implications. To foster higher levels of PSM in employees and enhance their job performance, Chinese public organizations should consider identifying and promoting servant leaders. Potential leaders can be screened through personality questionnaires to test their level of care and concern for others along the servant leadership dimensions described above. Vignettes may also be used to assess how potential leaders react to different scenarios.

Chinese public organizations should also provide servant leadership training to managerial-level employees. First, participants could make a self-assessment about their own servant leadership behaviour and could also receive anonymous feedback about their servant leadership competency from their subordinates, colleagues, and supervisors. This feedback could, for example, be collected as part of the 'democratic appraisals' in which bureau chiefs and all managers in charge of departments at the local level and above are evaluated anonymously by their subordinates each year, a practice that is a continuation of the traditional Chinese mass line approach (Liu and Dong 2012). Servant leadership training should encompass a mixture of training workshops focusing on specific topics (e.g., putting employees first, empowering employees, and helping employees succeed) and role-specific initiatives such as mentoring employees and being mentored, engaging followers in ethical conversations, and performing acts of service at work and in the greater community. It is crucial that servant leaders be encouraged to foster and develop the altruistic behaviours that 
This is the accepted version of an article accepted for publication in Public Administration Vol. 94 No. 4, 1025-1041. For

the full citation information and a link to the final Wiley published article please see: http://dx.doi.org/ 10.1111/padm.12266

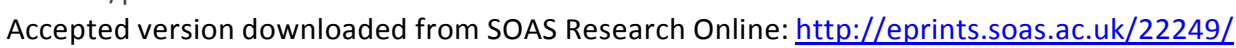

characterize PSM in their employees. For example, leaders should consider displaying service-oriented behaviours to their employees on a daily basis, which will allow employees to model their behaviours.

The need for leadership training for Chinese civil servants was first acknowledged by the national human resource conference in December 2003. The national human resource development strategy presented at the conference mandated that all public sector employees above the division chief level have to attend a three-month training session within a five-year period, predominately held at the administration schools that were established in the aftermath of the enactment of the Provisional Regulations on State Civil Servants (Zhang and Zhou 2010). In May 2010, a second national human resource conference was held that presented the Outline of National Median and Long Range Plan for Human Resource Development (Xue and Liou 2012). This document emphasized the need to not only focus on the development of senior officials but also foster the leadership skills of mid-level civil servants. This leadership training should encourage subordinates to practice a service orientation and integrity in their work. Assessing servant leadership competencies in the annual employee evaluation (Liu and Dong 2012) would underscore their importance to leaders and followers alike and expedite the dissemination of servant leadership practices within the Chinese public sector.

One of the main reasons for the enactment of the Civil Service Law was to improve the performance of civil servants. In our study, servant leadership was found to influence performance through increasing PSM. Hence, government agencies that face challenges meeting their performance targets may be well advised to adopt servant leadership practices (Li 2015). While in the past resources for training were more readily available for civil servants located at the centre in Beijing and the affluent coastal areas (Burns 2007), supervisors from all regions should be provided with equal access to servant leadership 
This is the accepted version of an article accepted for publication in Public Administration Vol. 94 No. 4, 1025-1041. For

the full citation information and a link to the final Wiley published article please see: http://dx.doi.org/ 10.1111/padm.12266

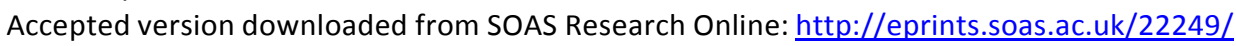

training. Testing leadership attitudes before and after training sessions and using control groups consisting of supervisors who have not yet been trained can help verify whether the training sessions improve their leadership skills and, ultimately, the performance of their employees and agencies.

\section{CONCLUSION}

This article has continued the recent research into servant leadership within the public sector by analysing the role of PSM in the servant leadership/job performance relationship. Using three waves of multi-source and multi-level data from employees in a Chinese government agency, PSM is found to mediate the influence of servant leadership on job performance. In addition to making a practical contribution, the present study also makes a theoretical contribution by establishing the social learning processes that link servant leadership to job performance.

Our research has limitations regarding its generalizability, given that it was conducted in only one government agency in a collectivistic cultural context. For example, prior research has cautioned against making direct comparisons of PSM across nations (Kim et al. 2013). Similarly, Van Dierendonck (2011) noted that cultures with low power distance may be more encouraging for the development of servant leadership, given that differences between leaders and followers are less pronounced. To examine the generalizability of the findings future research should replicate our study across different cultural and organizational contexts. In addition, as there is evidence that leaders exposed to a turbulent and contradictory institutional environment are more likely to diverge from the existing organizational norms, e.g., pleasing superiors instead of followers (Battilana et al. 2009), future studies that examine servant leadership in the public sector should be conducted in countries and/or agencies that are embedded in a more stable environment. Future research 
This is the accepted version of an article accepted for publication in Public Administration Vol. 94 No. 4, 1025-1041. For the full citation information and a link to the final Wiley published article please see: http://dx.doi.org/ 10.1111/padm.12266

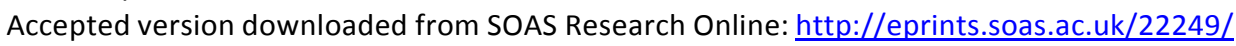

may also analyse the performance effects of servant leadership and PSM on job performance using an experimental methodology to test the robustness of our findings (Bellé 2013).

A further limitation comes from the fact that our article focuses on the individual level of analysis. We do not suggest that individual actions are the only causes of institutional change. Future research is also necessary to analyse the conditions that must be met in terms of organizational structures, control mechanisms and leadership autonomy for servant leadership to emerge and fully achieve its effects. In examining these issues researchers may consider drawing upon person-situation interactionist perspectives (Mischel 1977) and contingency approaches to leadership (Kerr et al. 1974). Whereas person-situation interactionist theories may explain how the organizational context in which the leader is based predicts the emergence of servant leadership, contingency theory may explain in which organizational contexts servant leadership is likely to have the strongest influence.

Finally, it would be of interest to study not only whether PSM mediates the relationship between individual leadership styles such as servant leadership and follower job performance but whether it also mediates the effects of distributed leadership (Van Wart 2013), that challenges existing leader-centric paradigms by arguing that leadership should be broadly disseminated through multiple employees. In China, for example, the CCP insists on the principle of collective leadership, which requires that important decisions are made by all party committee members instead of only the party secretary (Wang 2012). As these approaches become more popular in public organizations internationally (Currie et al. 2009), greater attention to their configuration and outcomes must be paid. 
This is the accepted version of an article accepted for publication in Public Administration Vol. 94 No. 4, 1025-1041. For the full citation information and a link to the final Wiley published article please see: http://dx.doi.org/ 10.1111/padm.12266

Accepted version downloaded from SOAS Research Online: http://eprints.soas.ac.uk/22249/

\section{REFERENCES}

Bandura, A. 1977. Social Learning Theory. Englewood Cliffs, NJ: Prentice-Hall.

Bass, B.M. 1985. Leadership and Performance Beyond Expectations. New York: Free Press.

Battilana, J., B. Leca and E. Boxenbaum. 2009. 'How Actors Change Institutions: Towards a Theory of Institutional Entrepreneurship', The Academy of Management Annals, 3, 1, $65-107$.

Bellé, N. 2013. 'Experimental Evidence on the Relationship between Public Service Motivation and Job Performance', Public Administration Review, 73, 1, 143-53.

Boin, A. and P. 't Hart. 2003. 'Public Leadership in Times of Crisis: Mission Impossible?', Public Administration Review, 63, 5, 544-53.

Bozeman, B. and X. Su. 2015. 'Public Service Motivation Concepts and Theory: A Critique', Public Administration Review, 75, 5, 700-10.

Bright, L. 2007. 'Does Person-Organization Fit Mediate the Relationship between Public Service Motivation and the Job Performance of Public Employees?' Review of Public Personnel Administration, 27, 4, 361-79.

Brislin, R. 1993. Understanding Culture's Influence on Behavior. Fort Worth, TX: Harcourt Brace Publishers.

Bryson, J.M. 2004. 'What to Do when Stakeholders Matter', Public Management Review, 6, $1,21-53$.

Burns, J.M. 1978. Leadership. New York: Harper \& Row.

Burns, J.P. 2007. 'Civil Service Reform in China', OECD Journal on Budgeting, 7, 1, 1-25.

Caillier, J.G. 2010. 'Factors Affecting Job Performance in Public Agencies', Public Performance \& Management Review, 34, 2, 139-65. 
This is the accepted version of an article accepted for publication in Public Administration Vol. 94 No. 4, 1025-1041. For the full citation information and a link to the final Wiley published article please see: http://dx.doi.org/ 10.1111/padm.12266

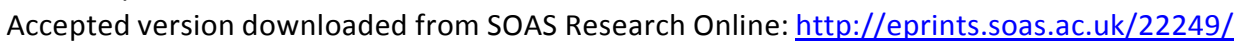

Chen, C.-A., C.-W. Hsieh and D.-Y. Chen. 2014. 'Fostering Public Service Motivation through Workplace Trust: Evidence from Public Managers in Taiwan', Public Administration, 92, 4, 954-73.

Currie, G., A. Lockett and O. Suhomlinova. 2009. 'The Institutionalization of Distributed Leadership: A Catch 22 in English Public Services', Human Relations, 62, 11, 173561.

DiMaggio, P.J. 1988. 'Interest and Agency in Institutional Theory', in L.G. Zucker (ed), Institutional Patterns and Organizations. Cambridge, MA: Ballinger. 3-22.

Dong, K.Y, H.S. Yang and X.H. Wang. 2010. 'Public Service Ethics and Anticorruption Efforts in Mainland China', in E.M. Berman, M.J. Moon and H. Choi (eds), Public Administration in East Asia: Mainland China, Japan, South Korea, and Taiwan. New York: Taylor and Francis, pp. 95-115.

Ehrhart, M.G. 2004. 'Leadership and Procedural Justice Climate as Antecedents of Unit-level Organizational Citizenship Behavior', Personnel Psychology, 57, 1, 61-94.

Entwistle, T. 2010. 'For Appropriateness or Consequences? Explaining Organizational Change in English Local Government', Public Administration, 89, 2, 661-80.

Eva, N., S. Sendjaya and D. Prajogo. 2013. 'Servant Leadership and Job Satisfaction: The Moderating Roles of Leader's Decision Making Process and Organizational Structure', Working Paper. Presented at the Annual Meeting of the Academy of Management, August 9-13.

Fernandez, S. and T. Moldogaziev. 2011. 'Empowering Public Sector Employees to Improve Performance: Does It Work?', American Review of Public Administration, 41, 1, 2347.

Graham, J.W. 1991. 'Servant-leadership in Organizations: Inspirational and Moral', Leadership Quarterly, 2, 2, 105-19. 
This is the accepted version of an article accepted for publication in Public Administration Vol. 94 No. 4, 1025-1041. For the full citation information and a link to the final Wiley published article please see: http://dx.doi.org/ 10.1111/padm.12266

Accepted version downloaded from SOAS Research Online: http://eprints.soas.ac.uk/22249/

Greenleaf, R.K. 1977. Servant Leadership: A Journey into the Nature of Legitimate Power and Greatness. New York: Paulist Press.

Greenleaf, R.K. 1972. The Institution as Servant. Cambridge, MA: Center for Applied Studies.

Han, Y., N.K. Kakabadse and A. Kakabadse. 2010. 'Servant Leadership in the People's Republic of China: A Case Study of the Public Sector', Journal of Management Development, 29, 3, 265-81.

Heilman, M.E., C.J. Block and J.A. Lucas. 1992. 'Presumed Incompetent? Stigmatization and Affirmative Action Efforts', Journal of Applied Psychology, 77, 4, 536-44.

Holm, P. 1995. 'The Dynamics of Institutionalization: Transformation Processes in Norwegian Fisheries', Administrative Science Quarterly, 40, 3, 398-422.

Holzer, M. and M. Zhang. 2009. 'Introduction to the Special Issue on Comparative Chinese/American Public Administration', Public Administration Review, 69, S1, S512.

Huang, X., K. Shi, Z. Zhang, and Y.L. Cheung. 2006. 'The Impact of Participative Leadership Behavior on Psychological Empowerment and Organizational Commitment in Chinese State-Owned Enterprises: The Moderating Role of Organizational Tenure', Asia Pacific Journal of Management, 23, 345-67.

Hunter, E.M., M.J. Neubert, S.J. Perry, L. A. Witt, L.M. Penney and E. Weinberger. 2013. 'Servant Leaders Inspire Servant Followers: Antecedents and Outcomes for Employees and the Organization', Leadership Quarterly, 24, 2, 316-31.

Jaramillo, F., D.B. Grisaffe, L.B. Chonko and J.A. Roberts. 2009. 'Examining the Impact of Servant Leadership on Sales Force Performance', Journal of Personal Selling and Sales Management, 29, 3, 257-75. 
This is the accepted version of an article accepted for publication in Public Administration Vol. 94 No. 4, 1025-1041. For the full citation information and a link to the final Wiley published article please see: http://dx.doi.org/ 10.1111/padm.12266

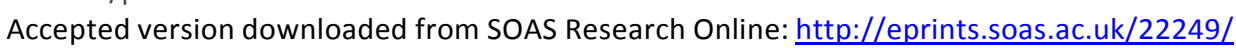

Kerr, S, C.A. Schriesheim, C.J. Murphy and R.M. Stogdill. 1974. 'Toward a Contingency Theory of Leadership Based upon the Consideration and Initiating Structure Literature'. Organizational Behavior and Human Performance, 12, 1, 62-82.

Kim, S., W. Vandenabeele, B.E. Wright, L.B. Andersen, F.P. Andersen, R.K. Christensen, C. Desmarais, M. Koumenta, P. Leisink, L. Bancheng, J. Palidauskaite, L. H. Pedersen, J.L. Perry, A. Ritz, J. Taylor and P. De Vivo. 2013. Investigating the Structure and Meaning of Public Service Motivation across Populations: Developing an International Instrument and Addressing Issues of Measurement Invariance. Journal of Public Administration Research and Theory, 23, 1, 79-102.

Ko, K. and L. Han. 2013. 'An Empirical Study on Public Service Motivation of the Next Generation Civil Servants in China', Public Personnel Management, 42, 2, 191-222. Kroll, A. and D. Vogel. 2014. 'The PSM-Leadership Fit: A Model of Performance Information Use', Public Administration, 92, 4, 974-91.

Leisink, P. and B. Steijn. 2009. 'Public Service Motivation and Job Performance of Public Sector Employees in the Netherlands', International Review of Administrative Sciences, 75, 1, 35-52.

Li, J. 2015. 'The Paradox of Performance Regimes: Strategic Responses to Target Regimes in Chinese Local Government', Public Administration, 93, 4, 1152-67.

Liden, R.C., S.J. Wayne, J.D., Meuser, J. Hu, J. Wu and C. Liao. 2015. 'Servant Leadership: Validation of a Short Form of the SL-28', The Leadership Quarterly, 26, 2, 254-69.

Liden, R.C., S.J. Wayne, H. Zhao and D. Henderson. 2008. 'Servant Leadership: Development of a Multidimensional Measure and Multi-level Assessment', Leadership Quarterly, 19, 2, 161-77. 
This is the accepted version of an article accepted for publication in Public Administration Vol. 94 No. 4, 1025-1041. For the full citation information and a link to the final Wiley published article please see: http://dx.doi.org/ 10.1111/padm.12266

Accepted version downloaded from SOAS Research Online: http://eprints.soas.ac.uk/22249/

Liden, RC., S.J. Wayne, C. Liao and J.D. Meuser. 2014. 'Servant Leadership and Serving Culture: Influence on Individual and Unit Performance', Academy of Management Journal, 57, 5, 1434-52.

Liu, B., and J.L. Perry. 2016. 'The Psychological Mechanisms of Public Service Motivation:

A Two-Wave Examination.' Review of Public Personnel Administration, 36, 4-30.

Liu, B., N. Tang and X. Zhu. 2008. 'Public Service Motivation and Job Satisfaction in China: An Investigation of Generalisability and Instrumentality.' International Journal of Manpower, 29, 684-99.

Liu, B., T. L. P. Tang and K. Yang. 2015. 'When Does Public Service Motivation Fuel the Job Satisfaction Fire? The Joint Moderation of Person-Organization Fit and NeedsSupplies Fit.' Public Management Review, 17, 876-900.

Liu, L. 2015. 'Over 1.3 Million Hopefuls Sit Chinese Civil Service Exam, Competing for Just 27,000 Jobs'. Shanghaiist, 29 November.

Liu, X. and K. Dong. 2012. 'Development of the Civil Servants' Performance Appraisal System in China: Challenges and Improvements', Review of Public Personnel Administration, 32, 2, 134-48.

Ma, L. 2015. 'Performance Feedback, Government Goal-Setting and Aspiration Level Adaptation: Evidence from Chinese Provinces. Public Administration, forthcoming. March, J.G. and J.P. Olsen. 1996. 'Institutional Perspectives on Political Institutions', Governance, 9, 3, 247-64.

Miao, Q., A. Newman, G. Schwarz and L. Xu. 2014. 'Servant Leadership, Trust, and the Organizational Commitment of Public Sector Employees in China', Public Administration, 92, 3, 727-43. 
This is the accepted version of an article accepted for publication in Public Administration Vol. 94 No. 4, 1025-1041. For the full citation information and a link to the final Wiley published article please see: http://dx.doi.org/ 10.1111/padm.12266

Accepted version downloaded from SOAS Research Online: http://eprints.soas.ac.uk/22249/

Mischel, W. 1977. 'The Interaction of Person and Situation', in D. Magnusson and N.S. Endler (eds), Personality at the Crossroads: Current Issues in Interactional Psychology, Hillsdale, NJ: Lawrence Erlbaum, pp. 333-52.

Perry, J.L. 1996. 'Measuring Public Service Motivation: An Assessment of Construct Reliability and Validity', Journal of Public Administration Research and Theory, 6, 1, $5-22$.

Perry, J.L., A. Hondeghem and L.R. Wise. 2010. 'Revisiting the Motivational Bases of Public Service: Twenty Years of Research and an Agenda for the Future', Public Administration Review, 70, 5, 681-90.

Perry, J.L. and L.R. Wise. 1990. 'The Motivational Bases of Public Service', Public Administration Review, 50, 3, 367-73.

Podsakoff, P.M., S.B. MacKenzie and N.P. Podsakoff. 2012. 'Sources of Method Bias in Social Science Research and Recommendations on How to Control it', Annual Review of Psychology, 63, 539-69.

Preacher, K.J., and J.P. Selig. 2012. 'Advantages of Monte Carlo Confidence Intervals for Indirect Effects', Communication Methods and Measures, 6, 2, 77-98.

Sendjaya, S., J.C. Sarros and J.C. Santora. 2008. 'Defining and Measuring Servant Leadership Behaviour in Organizations', Journal of Management Studies, 45, 2, 40224.

Shapiro, D.L. and B.L. Kirkman. 2001. 'Anticipatory Injustice: The Consequences of Expecting Injustice in the Workplace', in J. Greenberg and R. Cropanzano (eds), Advances in Organizational Justice. Stanford, CA: Stanford University Press, pp. $152-78$.

Stazyk, E.C. and R.S. Davis. 2005. 'Taking the 'High' Road: Does Public Service Motivation Alter Ethical Decision Making Processes?' Public Administration, 93, 3, 627-45. 
This is the accepted version of an article accepted for publication in Public Administration Vol. 94 No. 4, 1025-1041. For the full citation information and a link to the final Wiley published article please see: http://dx.doi.org/ 10.1111/padm.12266

Accepted version downloaded from SOAS Research Online: http://eprints.soas.ac.uk/22249/

Stone, A.G., R. Russell and K. Patterson. 2004. 'Transformational versus Servant Leadership: A Difference in Leader Focus', Leadership \& Organization Development Journal, 25, 4, 349-61.

Tabachnick, B.G. and L.S. Fidell. 2013. Using Multivariate Statistics $\left(6^{\text {th }}\right.$ ed.). Boston: Pearson.

Van Dierendonck, D. 2011. 'Servant Leadership: A Review and Synthesis', Journal of Management, 37, 4, 1228-61.

Van Wart, M. 2013. 'Administrative Leadership Theory: A Reassessment after 10 Years', Public Administration, 91, 3, 521-43.

Vandenabeele, W. 2009. 'The Mediating Effect of Job Satisfaction and Organizational Commitment on Self-Reported Performance: More Robust Evidence of the PSMPerformance Relationship', International Review of Administrative Sciences, 75, 1, $53-78$.

Vandenabeele, W., G.A. Brewer and A. Ritz. 2014. 'Past, Present, and Future of Public Service Motivation Research', Public Administration, 92, 4, 779-89.

Vermeeren, B., B. Kuipers and B. Steijn. 2014. 'Does Leadership Style Make a Difference? Linking HRM, Job Satisfaction, and Organizational Performance', Review of Public Personnel Administration, 34, 2, 174-95.

Wang, X. 2012. China's Civil Service Reform. London: Routledge.

Wright, B.E., D.P. Moynihan and S.K. Pandey. 2012. 'Pulling the Levers: Transformational Leadership, Public Service Motivation, and Mission Valence', Public Administration Review, 72, 2, 206-15.

Wright, B.E. and A.M. Grant. 2010. 'Unanswered Questions about Public Service Motivation: Designing Research to Address Key Issues of Emergence and Effects', Public Administration Review, 70, 5, 691-700. 
This is the accepted version of an article accepted for publication in Public Administration Vol. 94 No. 4, 1025-1041. For the full citation information and a link to the final Wiley published article please see: http://dx.doi.org/ 10.1111/padm.12266

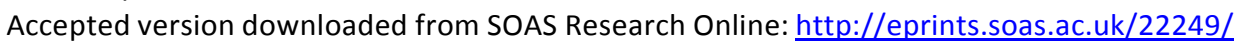

Xue, L. and K.T. Liou. 2012. 'Government Reform in China: Concepts and Reform Cases', Review of Public Personnel Administration, 32, 2, 108-14.

Zhang, M. and W. Zhou. 2010. 'Civil Service Reform in Mainland China', in E.M. Berman, M.J. Moon and H. Choi (eds), Public Administration in East Asia: Mainland China, Japan, South Korea, and Taiwan. New York: Taylor and Francis, pp. 145-63. 
This is the accepted version of an article accepted for publication in Public Administration Vol. 94 No. 4, 1025-1041. For the full citation information and a link to the final Wiley published article please see: http://dx.doi.org/ 10.1111/padm.12266

Accepted version downloaded from SOAS Research Online: http://eprints.soas.ac.uk/22249/

TABLE 1 Results of confirmatory factor analysis

\begin{tabular}{lccccc}
\hline Model & $\mathbf{X}^{2}$ & $\boldsymbol{D} \boldsymbol{f}$ & TLI & CFI & RMSEA \\
\hline Hypothesized three-factor model & 482 & 206 & .96 & .97 & .07 \\
Two-factor model: Servant leadership and & & & & & \\
PSM combined & 776 & 208 & .91 & .92 & .10 \\
One-factor model & 943 & 209 & .89 & .91 & .12
\end{tabular}

Note. $\mathrm{X}^{2}$, Satorra-Bentler scaled chi-square; TLI, Tucker-Lewis fit index; CFI, comparative fit index; RMSEA, root-mean-square error of approximation.

TABLE 2 Means, standard deviations, and correlations among the study variables

\begin{tabular}{|c|c|c|c|c|c|c|c|c|}
\hline \multicolumn{2}{|c|}{ Variable } & $M$ & $S D$ & 1 & 2 & 3 & 4 & 5 \\
\hline 1 & Job performance & 4.16 & 0.56 & - & & & & \\
\hline 2 & Servant leadership & 3.83 & 0.28 & .06 & - & & & \\
\hline 3 & PSM & 3.47 & 0.66 & $.19^{* *}$ & $.36^{* *}$ & - & & \\
\hline 4 & $\begin{array}{l}\text { Time under } \\
\text { supervisor }\end{array}$ & 3.93 & 2.96 & -.03 & -.08 & -.04 & - & \\
\hline 5 & $\begin{array}{l}\text { Organizational } \\
\text { tenure }\end{array}$ & 6.90 & 5.86 & .03 & -.12 & -.03 & $.51 * *$ & - \\
\hline 6 & Gender & 0.68 & 0.47 & .08 & -.12 & $.23 * *$ & .02 & .01 \\
\hline
\end{tabular}

Note. Gender coded $1=$ male, $0=$ female. Servant leadership scores aggregated to team level.

$* p<.05, * * p<.01$. 
This is the accepted version of an article accepted for publication in Public Administration Vol. 94 No. 4, 1025-1041.

For the full citation information and a link to the final Wiley published article please see: http://dx.doi.org/ 10.1111/padm.12266

Accepted version downloaded from SOAS Research Online: http://eprints.soas.ac.uk/22249/

TABLE 3 Results of multi-level mediated regression analyses

Model 1 Model 2

PSM Job performance

\section{Level-1}

Time under

supervisor

Organizational tenure

Gender

PSM

Level-2

Servant leadership

$.39 * *$ .21

$R^{2}(\mathrm{OLS})$

.01

.05

$-.02$

$.14 *$ .04

Note. Standardized regression coefficients reported. Gender coded $1=$ male, $0=$ female.

$* p<.05, * * p<.01$. 
This is the accepted version of an article accepted for publication in Public Administration Vol. 94 No. 4, 10251041. For the full citation information and a link to the final Wiley published article please see: http://dx.doi.org/ 10.1111/padm.12266

Accepted version downloaded from SOAS Research Online: http://eprints.soas.ac.uk/22249/

\section{FIGURE 1 Standardized regression results of the multi-level mediation model}

Team

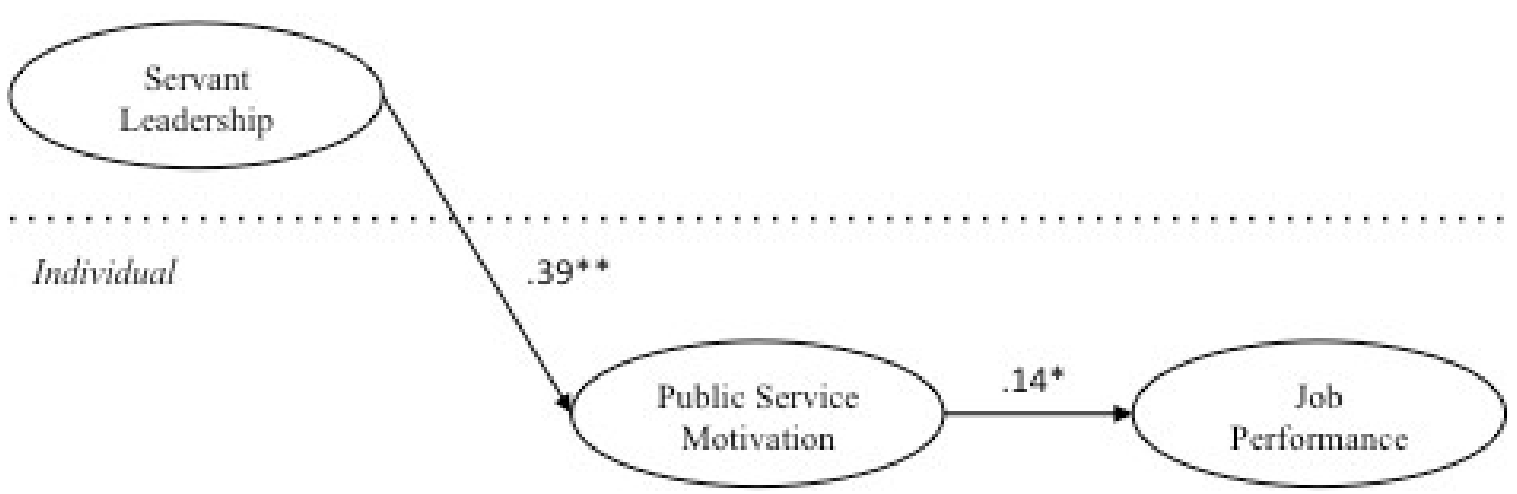

$* p<.05, * * p<.01$. 
This is the accepted version of an article accepted for publication in Public Administration Vol. 94 No. 4, 1025-1041. For the full citation information and a link to the final Wiley published article please see: http://dx.doi.org/ 10.1111/padm.12266

Accepted version downloaded from SOAS Research Online: http://eprints.soas.ac.uk/22249/

\section{APPENDIX: STUDY SCALE ITEMS, MEANS, STANDARD DEVIATIONS, AND STANDARDIZED FACTOR LOADINGS}

\begin{tabular}{|c|c|c|c|c|}
\hline Scale & Items & Mean & $\begin{array}{l}\text { Standard } \\
\text { Deviation }\end{array}$ & $\begin{array}{r}\text { Factor } \\
\text { Loading }\end{array}$ \\
\hline \multirow[t]{14}{*}{$\begin{array}{l}\text { Servant } \\
\text { Leadership }\end{array}$} & $\begin{array}{l}\text { My supervisor spends the time to form quality } \\
\text { relationships with employees. }\end{array}$ & 3.80 & .91 & .57 \\
\hline & $\begin{array}{l}\text { My supervisor creates a sense of community } \\
\text { among employees. }\end{array}$ & 4.02 & .85 & .71 \\
\hline & $\begin{array}{l}\text { My supervisor's decisions are influenced by } \\
\text { employees' input. }\end{array}$ & 3.69 & .86 & .51 \\
\hline & $\begin{array}{l}\text { My supervisor tries to reach consensus among } \\
\text { employees on important decisions. }\end{array}$ & 3.90 & .81 & .70 \\
\hline & $\begin{array}{l}\text { My supervisor is sensitive to employees' } \\
\text { responsibilities outside the work place. }\end{array}$ & 3.47 & .96 & .38 \\
\hline & $\begin{array}{l}\text { My supervisor makes the personal development of } \\
\text { employees a priority. }\end{array}$ & 3.67 & .85 & .59 \\
\hline & $\begin{array}{l}\text { My supervisor holds employees to high ethical } \\
\text { standards. }\end{array}$ & 3.79 & .82 & .65 \\
\hline & My supervisor does what she or he promises to do. & 3.92 & .90 & .73 \\
\hline & $\begin{array}{l}\text { My supervisor balances concern for day-to-day } \\
\text { details with projections for the future. }\end{array}$ & 3.90 & .77 & .72 \\
\hline & $\begin{array}{l}\text { My supervisor displays wide-ranging knowledge } \\
\text { and interests in finding solutions to work problems. }\end{array}$ & 3.88 & .79 & .73 \\
\hline & $\begin{array}{l}\text { My supervisor makes me feel like I work with } \\
\text { him/her, not for him/her. }\end{array}$ & 3.94 & .84 & .73 \\
\hline & $\begin{array}{l}\text { My supervisor works hard at finding ways to help } \\
\text { others be the best they can be. }\end{array}$ & 3.93 & .80 & .76 \\
\hline & $\begin{array}{l}\text { My supervisor encourages employees to be } \\
\text { involved in community service and volunteer } \\
\text { activities outside of work. }\end{array}$ & 3.81 & .82 & .66 \\
\hline & $\begin{array}{l}\text { My supervisor emphasizes the importance of } \\
\text { giving back to the community. }\end{array}$ & 3.92 & .81 & .68 \\
\hline \multirow{5}{*}{$\begin{array}{l}\text { Pubic Service } \\
\text { Motivation }\end{array}$} & Meaningful public service is very important to me. & 3.61 & .82 & .76 \\
\hline & $\begin{array}{l}\text { I am often reminded by daily events about how } \\
\text { dependent we are on one another. }\end{array}$ & 3.53 & .85 & .78 \\
\hline & $\begin{array}{l}\text { Making a difference in society means more to me } \\
\text { than personal achievements. }\end{array}$ & 3.60 & .81 & .66 \\
\hline & $\begin{array}{l}\text { I am prepared to make enormous sacrifices for the } \\
\text { good of society. }\end{array}$ & 3.38 & .85 & .72 \\
\hline & $\begin{array}{l}\text { I am not afraid to go to bat for the rights of others } \\
\text { even if it means I will be ridiculed. }\end{array}$ & 3.19 & .90 & .65 \\
\hline Job & $\mathrm{He} /$ she is very competent. & 4.09 & .67 & .65 \\
\hline \multirow[t]{2}{*}{ Performance } & $\mathrm{He} /$ she gets his/her work done very effectively. & 4.21 & .71 & .84 \\
\hline & $\mathrm{He} /$ she has performed his/her job well. & 4.19 & .71 & .57 \\
\hline
\end{tabular}

